\section{HTA in the United Kingdom}

doi:10.1017/S0266462310000140

To the Editor:

I was dismayed to find that the article on HTA in the United Kingdom in the recent Special Issus of IJTAHC on the History of HTA (1) makes so little mention of the main component of HTA in England and Wales, namely the NHS HTA Programme. That seems a puzzling oversight for a program that, since its inception in 1993, has spent 138 million GBP on commissioning nearly 850 in-depth HTA studies, sifted and prioritized from some 15,000 suggestions drawn from all quarters of UK health service, policy, and research worlds. From these, it has published nearly 500 full-length HTA monographs (with over 125 more currently in editorial review) in the series Health Technology Assessment, which has attracted over 15 million downloads as well as being distributed in hard copy to just over 128,000 recipients. Around 120 of these monographs resulted from research commissioned explicitly to advance the methodology of HTA-a contribution that is unique among the world's HTA agencies. This stream of HTA publications, which has also spawned countless summaries, local adaptations, translations, academic papers, and other spinoffs, has had an acknowledged impact throughout the world of HTA.

Such a large undertaking surely merited more than the few lines that it was afforded in the article. The program's under-representation would both surprise and disappoint the thousands of academics, clinicians, policy makers, managers, and health service users-not to mention the 8,000 patients enrolled into UK HTA trials-who have been involved in some way or another in identifying and prioritizing the HTA topics, commissioning and carrying out the scientific work, and publishing, disseminating and implementing the results. Perhaps the journal should at some stage seek to rectify this astonishing omission, if only to acknowledge their efforts and those of the hardworking staff past and present of the National Institute of Health Research National Evaluation, Trials and Studies Coordinating Centre (NETSCC, formerly known as NCCHTA).

Moreover, any authoritative and balanced history of UK HTA would also feature the pioneering work in the 1990s of the Scottish and regional HTA programs (respectively, the Scottish Health Purchasing Information Centre led by Norman Waugh and the regional Development and Evaluation Committees run by Andrew Stevens and others) that were the precursors of the NHS HTA Programme.

\section{REFERENCE}

1. Drummond M, Banta D. Health technology assessment in the United Kingdom. Int J Technol Assess Health Care. 2009;25(Suppl 1):178-181.

\author{
John Gabbay, FFPH \\ Emeritus Professor \\ University of Southampton \\ clo 1 Daniells Close \\ Lymington SO41 $3 P Q$ \\ United Kingdom \\ Email:jg3@soton.ac.uk
}

\section{HTA in the United Kingdom: Response}

\section{doi:10.1017/S0266462310000152}

To the Editor:

Professor Gabbay says he is dismayed that our article on the history of HTA in a recent special issue makes so little mention of the NHS HTA Programme, He calls this "a puzzling oversight," which "would both surprise and disappoint the thousands.... who have been involved in some way or 